\title{
THE COMPLEX CONTROLLER FOR THREE-PHASE INDUCTION MOTOR DIRECT TORQUE CONTROL
}

\author{
Alfeu J. Sguarezi Filho* \\ sguarezi@dsce.fee.unicamp.br
}

\author{
E. Ruppert Filho* \\ ruppert@fee.unicamp.br
}

*Universidade Estadual de Campinas, FEEC-DSCE

Av. Albert Einstein, 400

Cidade Universitária Zeferino Vaz, Campinas, SP

\begin{abstract}
This paper proposes a design and tuning method for a complex gain controller, based on the three-phase induction motor mathematical model complex transfer function to be used in the direct torque control at low speed which is a problem so far. The design and tuning of the complex gain is done by using the closed loop system frequency-response function. Experimental results are presented to validate the controller and operation at low speed is also explored.
\end{abstract}

KEYWORDS: Complex gain controller, Complex transfer function, Induction motor, Direct torque control.

\section{RESUMO}

Este trabalho propõe um método de projeto para um controlador de ganho complexo baseado na função de transferência complexa do motor de indução trifásico para uso no controle direto de torque em que a operação do motor em baixas velocidades é um problema. $\mathrm{O}$ projeto e a sintonia do ganho complexo é realizado com o emprego da resposta em frequência do sistema em malha fechada. Resultados experimentais são apresentados para a validação da proposta do controlador.

PALAVRAS-CHAVE: Controlador de ganho complexo,

Artigo submetido em 22/11/2008 (Id.: 00924)

Revisado em 26/02/2009

Aceito sob recomendação do Editor Associado Prof. Darizon Alves de Andrade
Função de Transferência Complexa, Motor de Indução, Controle direto de torque.

\section{INTRODUCTION}

The dynamics of the three-phase induction motor is traditionally described by differential equations. The space-vector concept (Kovács e Rácz, 1984) is used in the mathematical representation of the motor state variables such as voltage, current, and flux.

The concept of complex transfer function derives from the application of the Laplace transform to differential equations where the complex coefficients are in accordance with the spiral vector theory by Yamamura (1992).

Holtz (1995) proposed a three-phase induction motor mathematical model using the complex transfer function and presented the induction motor root locus. Other procedures for modeling and simulating the three-phase induction motor dynamics using the complex transfer function concept are also presented by Cad (2000).

Briz et al. (2000) applied the complex transfer function concept to design current regulators for RL loads and induction motors. The regulator design was implemented through the frequency-response function of the closed-loop complex transfer function of the controlled induction machine system in the synchronous reference frame. Experimental results showed good performance although the $d q$ stator currents had presented cross- 
coupling in the induction machine transients and lowspeed tests had not been shown.

To solve the cross-coupling between induction machine $d q$ transient stator currents Holtz et al. (2004) designed a stator-current controller using complex notation. From this, the current controller structure employing single-complex zeros is synthesized. Experimental results demonstrate that high dynamic performance and zero cross-coupling are achieved even at very low switching frequency although the speed control had not be presented.

An alternative for induction motor drives is the direct torque control (DTC), which consists of the direct control of the stator $\lambda_{1}$ and the electromagnetic torque $T_{e}$. DTC controllers generate a stator-voltage vector that allows quick torque response with the smallest variation of the stator flux. The principles of the DTC using histereses controllers and variable switching frequency were presented by Takahashi e Noguchi (1986) and Depenbrock (1988).

Xue et al. (1990) proposed a DTC strategy using PI controllers and space-vector modulation to generate a stator voltage based on torque and stator-flux errors. This strategy has presented good torque response although low-speed tests had not been shown so far.

The literature shows the application of the control theory to some DTC strategies, as that one presented by Buja e Kazmierkowski (2004) and other presented by Stojic e Vukosavic (2005). Each strategy aims to the torque and to the rotor or stator flux control although the complex transfer function of induction motor is not used.

This paper proposes a design and tuning method for a complex gain controller which is designed by using the induction motor complex transfer function to control the motor. The controller is adjusted by the frequencyresponse function of the closed loop system. Experimental results are presented for validation of the proposed controller including low speed operation.

\section{THE COMPLEX MATHEMATICAL MODEL OF THE THREE-PHASE INDUCTION MACHINE}

The three-phase induction machine mathematical model is written with the variables referred to the $d q$ synchronous reference frame and the complex state variables are the stator current $\vec{i}_{1 d q}$ and the stator flux $\vec{\lambda}_{1 d q}$.

$$
\begin{array}{r}
\vec{v}_{1 d q}=R_{1} \vec{i}_{1 d q}+\dot{\vec{\lambda}}_{1 d q}+j \omega_{1} \vec{\lambda}_{1 d q} \\
0=R_{2} \vec{i}_{2 d q}+\dot{\vec{\lambda}}_{2 d q}+j\left(\omega_{1}-P \omega_{m e c}\right) \vec{\lambda}_{2 d q}
\end{array}
$$

The relationship between currents and fluxes are given by

$$
\left[\begin{array}{l}
\vec{\lambda}_{1 d q} \\
\vec{\lambda}_{2 d q}
\end{array}\right]=\left[\begin{array}{cc}
L_{1} & L_{m} \\
L_{m} & L_{2}
\end{array}\right]\left[\begin{array}{l}
\vec{i}_{1 d q} \\
\vec{i}_{2 d q}
\end{array}\right]
$$

The electromagnetic torque and mechanical speed are given by

$$
T_{e}=\frac{3}{2} P \operatorname{Im}\left[\vec{i}_{1 d q} \operatorname{conj}\left(\vec{\lambda}_{1 d q}\right)\right]
$$

and

$$
J \frac{\omega_{m e c}}{d t}=T_{e}-T_{L}
$$

The subscripts 1,2 and $m$ represent the stator, rotor and magnetization parameters respectively, $\omega_{1}$ is the synchronous speed, $\omega_{m e c}$ is the machine speed, $R_{1}$ and $R_{2}$ are the estator and rotor windings per phase electrical resistance, $L_{1}, L_{2}$ and $L_{m}$ are the proper and mutual inductances of the stator and rotor windings, $\vec{v}$ is the voltage vector, $P$ is the machine number of pair of poles, $J$ is the load and rotor inertia moment and $T_{L}$ is the load torque.

By combining equations (1), (2) and (3), after some algebraic manipulations, one can write the complex space state equations as:

$$
\left[\begin{array}{l}
\dot{\vec{\lambda}}_{1 d q} \\
\dot{\vec{i}}_{1 d q}
\end{array}\right]=\left[\begin{array}{ll}
a_{1} & a_{2} \\
a_{3} & a_{4}
\end{array}\right]\left[\begin{array}{l}
\vec{\lambda}_{1 d q} \\
\vec{i}_{1 d q}
\end{array}\right]+\left[\begin{array}{l}
\vec{v}_{1 d q} \\
\frac{\vec{v}_{1 d q}}{\sigma L_{1}}
\end{array}\right]
$$

where

$$
a_{1}=-j \omega_{1}
$$

$$
a_{2}=-R_{1}
$$

$$
a_{3}=\left(\frac{R_{2}}{\sigma L_{1} l_{2}}-\frac{j P \omega_{m e c}}{\sigma L_{1}}\right)
$$

$$
a_{4}=-\left[\frac{R_{1}}{\sigma L_{1}}+\frac{R_{2}}{\sigma L_{2}}+j\left(\omega_{1}-P \omega_{m e c}\right)\right]
$$




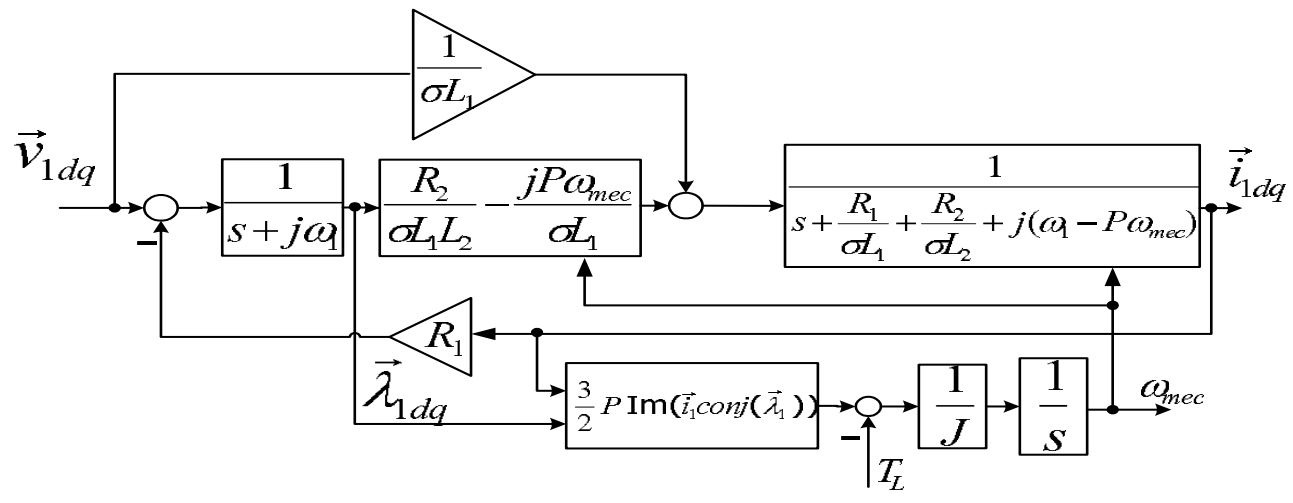

Figure 1: IM block diagram.

where $\sigma=1-\frac{L_{m}^{2}}{L_{1} L_{2}}$ is the leakage coefficient.

In order to obtain the induction motor complex transfer function the Laplace transform is applied to (6) in accordance with the complex transfer function concept, it is assumed that the mechanical time constant of the motor is much larger than the transient electromagnetic time constants and the saturation effects is neglected. Thus, $\omega_{m e c}=$ constant is a valid approximation (Yamamura, 1992; Holtz et al., 2004). The induction motor block diagram originated by use of (4), (5) and (6) is shown in Figure 1.

When designing the DTC control system, $\vec{v}_{1 d q}$ is considered as the input and the $\vec{i}_{1 d q}$ is considered as the output. Therefore the induction machine complex transfer function is given by

$$
H(s)=\frac{I_{1 d q}}{V_{1 d q}}=\frac{\left(\frac{s+j \omega_{1}}{\sigma L_{1}}\right)+a_{3}}{\left(s+j \omega_{1}\right)\left(s+a_{4}\right)+R_{1} a_{3}}
$$

where $I_{1 d q}=\mathcal{L}\left\{\vec{i}_{1 d q}\right\}$ and $V_{1 d q}=\mathcal{L}\left\{\vec{v}_{1 d q}\right\}$.

\section{DIRECT TORQUE CONTROL}

The direct torque control strategy allows a quick torque response and consists of the direct control of the stator flux $\lambda_{1}$ and the torque $T_{e}$. The flux and torque controllers generate a stator-voltage vector that allows quick torque response with the smallest variation of the stator flux.

This work is based in Xue's strategy as shown in (Xue et al., 1990) which uses conventional PI controllers and space-vector modulation to generate a stator voltage based on torque and stator-flux errors.
In this present work, by using stator-field orientation, the torque and stator flux must become parts of a complex number, where the magnitude of the stator flux $\lambda_{1}$ is the real component and the torque $T_{e}$ is the imaginary component. Hence, the reference signals and the error become a complex number and the proposed controller is a complex gain $(a+j b)$. This gain has the function to generate a voltage reference vector using the stator flux-torque vector error $\left(\varepsilon_{\lambda}+j \varepsilon_{T}\right)$. This way the stator-voltage vector in this control strategy is given by

$$
\vec{v}_{1 d q}=\left(\varepsilon_{\lambda}+j \varepsilon_{T}\right)(a+j b)
$$

which means

$$
v_{1 d}=\left(-\varepsilon_{T} b+\varepsilon_{\lambda} a\right)
$$

$$
v_{1 q}=\left(\varepsilon_{T} a+\varepsilon_{\lambda} b\right)
$$

where $a$ is the real part of the complex gain, $b$ is the imaginary part of the complex gain, $\varepsilon_{\lambda}$ is the flux error and $\varepsilon_{T}$ is the torque error.

The block diagram of the mathematical model of the control system proposed with the complex gain controller is presented in Figure 2.

It can be observed in equation (12) that the complex gain changes the amplitude and phase of the vector voltage due to the cross-coupling between the complex gain and the error vector.

The reference stator-voltage vector $\vec{v}_{1 d q}$ is transformed by using stator-flux position $\delta_{s}$ to obtain the stator voltage in the stationary reference frame $\alpha \beta$, as shown in the next section. 


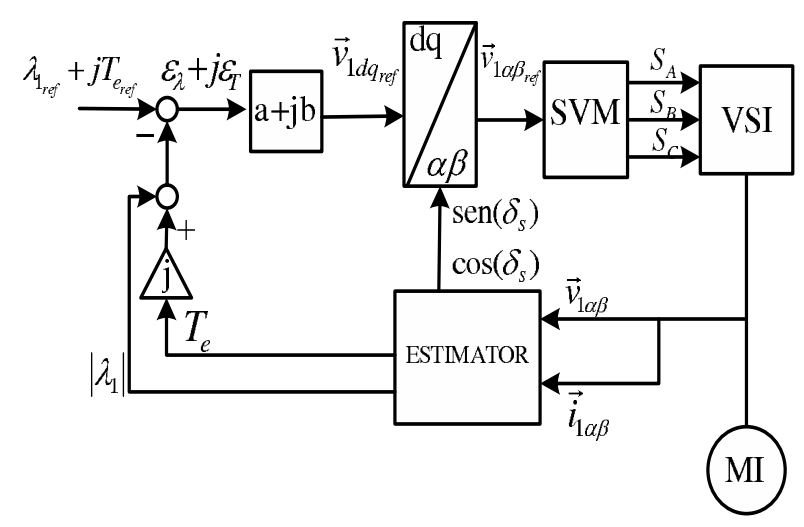

Figure 2: DTC strategy with complex controller.

\subsection{ESTIMATION BLOCK}

The estimation of the stator flux is calculated by using the stator currents and voltages, given by

$$
\vec{\lambda}_{1 \alpha \beta}=\int\left(f e m_{\alpha \beta}\right) d t=\int\left(\vec{v}_{1 \alpha \beta}-R_{1} \vec{i}_{1 \alpha \beta}\right) d t
$$

where the subscript $\alpha \beta$ is used to designate the stator stationary reference frame which is being used.

The stator-flux angle is estimated by using the trigonometric transfer function

$$
\delta_{s}=t g^{-1}\left(\frac{\lambda_{1 \beta}}{\lambda_{1 \alpha}}\right)
$$

In order to achieve the stator-flux estimation for a wide speed range in drives using (15) an integration method (Xu et al., 1988; Lins, 2001) given by (17) can be used.

$$
y=\frac{1}{s+\omega_{c}} x+\frac{\omega_{c}}{s+\omega_{c}} z
$$

where, $x$ is the input of the integrator, $z$ is the compensation signal and $\omega_{c}$ is the cut-off frequency.

Another way to obtain a better integrator performance for low speed, as shown in (17), it can be used a limiter (Hu e Wu, 1998). This implementation is shown in the block diagram of Figure 3.

\subsection{DESIGN OF THE COMPLEX GAIN}

The tuning operation of the complex gain controller requires the transfer function of the closed loop system, to obtain its frequency-response function.

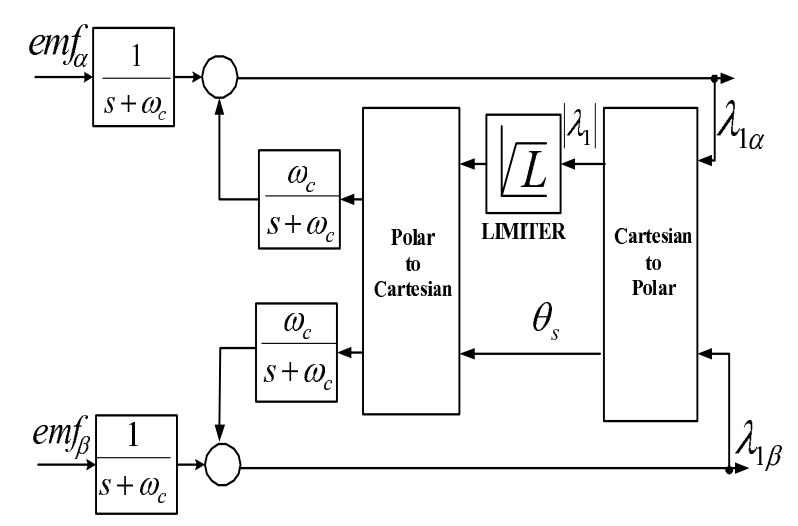

Figure 3: Integrator block diagram.

The frequency is chosen in accordance with the the induction motor desired speed operation to design the complex gain.

In accordance with the DTC control strategy the induction motor output has to be the stator flux magnitude $\lambda_{1}$ and the torque $T_{e}$. Therefore the $\mathrm{H}(\mathrm{s})$ in equation (11) outputs have to become the stator flux magnitude $\lambda_{1}$ and the torque $T_{e}$. The expression to obtain the stator flux by using the stator current $i_{1 d}$ is given by

$$
\lambda_{1}=\lambda_{1 d} \cong \sigma L_{1} i_{1 d}
$$

and to obtain the electromagnetic torque through Equation (4) in the $d q$ reference frame one may use the expression:

$$
T_{e}=\frac{3}{2} P \lambda_{1} i_{1 q}
$$

As the stator flux magnitude $\lambda_{1}$ is assumed to be essentially constant through of the equations (11), (18) and (19) the new transfer function is achieved with torque and flux as output and it is given by

$$
\frac{X_{\lambda T}}{V_{1 d q}}=H(s)\left(\sigma L_{1}+j P \frac{3}{2} \lambda_{1}\right)
$$

where $X_{\lambda T}=\mathcal{L}\left\{\lambda_{1}+j T_{e}\right\}$. The frequency-response function of Equation (20) is presented in Figure 4.

Then, from Equations (12) and (20) one obtain the control system block diagram wich is presented in Figure 5 .

The expression of the closed loop transfer function of the control system showed in Figure 5 is given by 


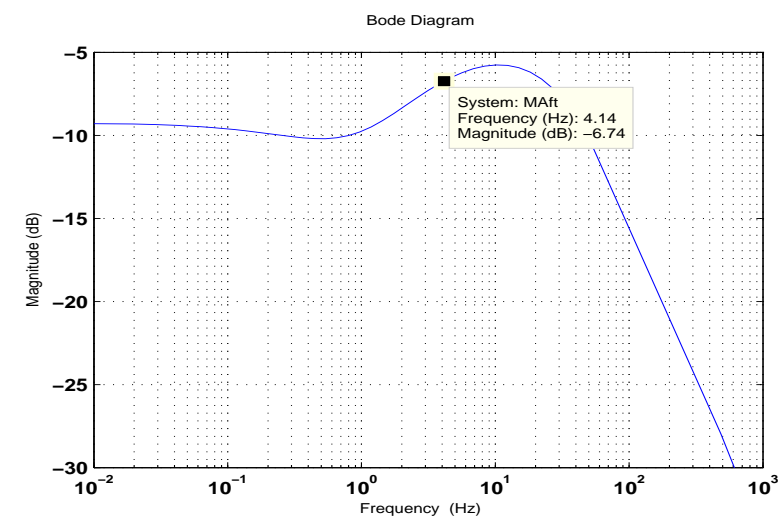

Figure 4: Equation (20) frequency-response function.

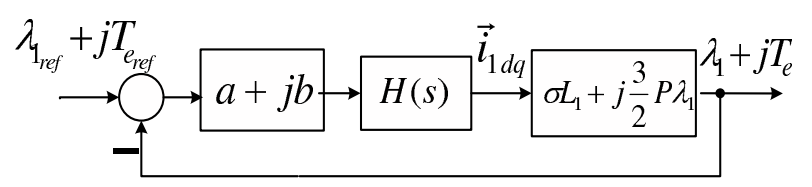

Figure 5: System to design the complex gain

$$
\frac{X_{\lambda T}}{X_{\lambda T_{r e f}}}=\frac{(a+j b) H(s)\left(\sigma L_{1}+j P \frac{3}{2} \lambda_{1}\right)}{1+(a+j b) H(s)\left(\sigma L_{1}+j P \frac{3}{2} \lambda_{1}\right)}
$$

where $X_{\lambda T_{r e f}}=\mathcal{L}\left\{\lambda_{1_{\text {ref }}}+j T_{e_{\text {ref }}}\right\}$. At the frequency of $4.16 \mathrm{~Hz}$ the complex gain is chosen by using simulations, considering slip approximately null and the Bode criterion. The complex gain found was $125-j 25$. The frequency-response function of Equation (21) is shown in Figure 6 and its magnitude is near $0 \mathrm{~dB}$.

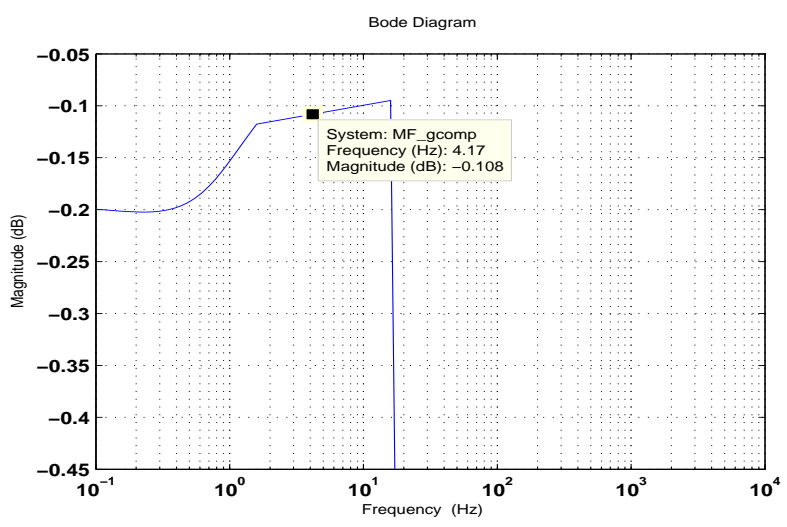

\section{EXPERIMENTAL RESULTS}

The DTC strategy was implemented using a Texas Instruments DSP TMS320F2812 platform. The system consists of a three-phase voltage source inverter with insulated-gate bipolar transistors (IGBTs) and the three-phase induction motor shown in the appendix. The stator voltage commands are modulated by using symmetrical space vector PWM, with switching frequency equal to $2.5 \mathrm{kHz}$. The $\mathrm{DC}$ bus voltage of the inverter is $226 \mathrm{~V}$. The stator voltages and currents are sampled in the frequency of $2.5 \mathrm{kHz}$. A conventional PI controller generates a torque reference by using the speed error. The flux and torque estimation, and the flux-torque complex regulator and speed controller have the same sampling frequency of $2.5 \mathrm{kHz}$. The encoder resolution is 1500 pulses per revolution.

Three no-load induction motor tests were made. The first one was the response to a torque step of $12.2 \mathrm{Nm}$ which is shown in Figure 7. The response of the DTC with complex controller presented a slightly better performance in transient and steady state when such response is compared with the response of DTC with PI controller. It can be observed that the response time is $25 \mathrm{~ms}$ and the reference is followed with a small oscillation. This oscillation occurs due to the natural lack of accuracy in the measurements of currents and voltages.

In the second test the speed varies in forward and reversal operation and the result is presented in Figure 8. The speed changes from $13 \mathrm{rad} / \mathrm{s}$ to $-13 \mathrm{rad} / \mathrm{s}$ in $1 \mathrm{~s}$ and the complex gain is not changed during the test. This result confirms the satisfactory performance and the robustness of the controller due to the fact that the the speed reaches the reference in several conditions. The responses of the DTC with complex controller and of the DTC with PI controller have the same performance in transient and steady state. The small error occurs due the natural lack of accuracy in the measurement of the speed.

Figure 9 presents the speed response when the speed varies from $6.28 \mathrm{rad} / \mathrm{s}$ to $-6.28 \mathrm{rad} / \mathrm{s}$. The response of the DTC control with complex controller presented a slightly better performance in steady state when such response is compared with the response of DTC with PI controller. The result confirms the satisfactory performance and the robustness of the controller again due to the fact that the speed reaches the reference value although the complex gain is designed for induction motor operation at $4.16 \mathrm{~Hz}$.

Figure 6: Equation (21) frequency-response function 


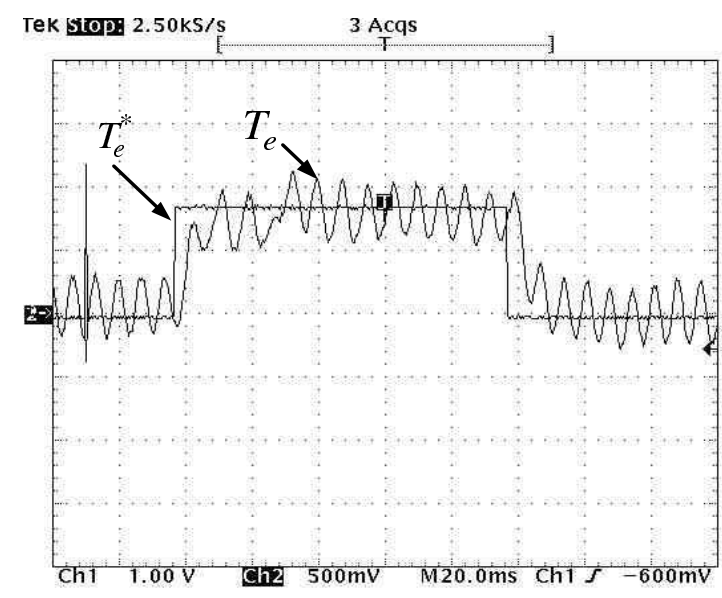

(a) DTC - $T_{e_{\text {ref }}}$ step input function with complex controller $(9 \mathrm{Nm} /$ div $)$.

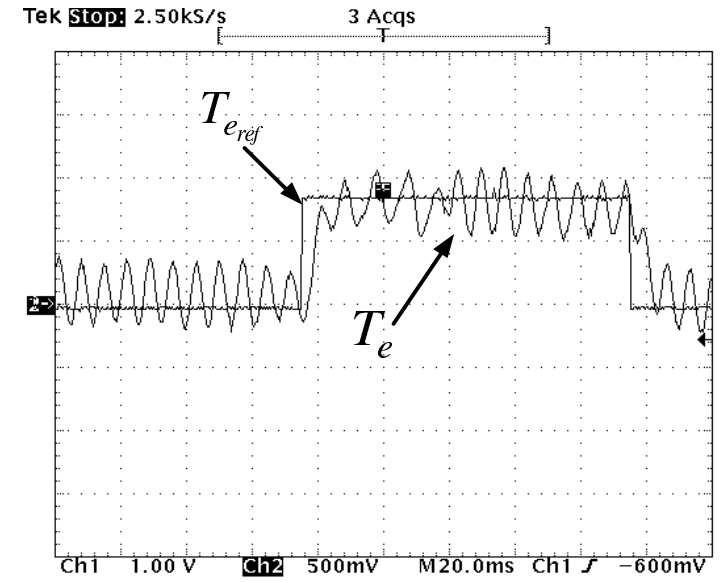

(b) DTC - $T_{e_{\text {ref }}}$ step input function with PI controller (9 $\mathrm{Nm} /$ div).

Figure 7: Responses to step torque operation.

\section{CONCLUSION}

The concept of complex vector notation associated with the complex gain controller allows the design and tuning the complex controller by using the closed loop system frequency response function.

The experimental results presented shows the satisfactory performance and the robustness of the controller due to the fact that the speed reaches the reference in many different conditions although the complex gain is designed for induction motor operation at $4.16 \mathrm{~Hz}$. Thus, the design of complex gain has an acceptable robustness although a detailed analysis considering parameters variations and other several speed operations have to be done. Due to the variable speed operation it

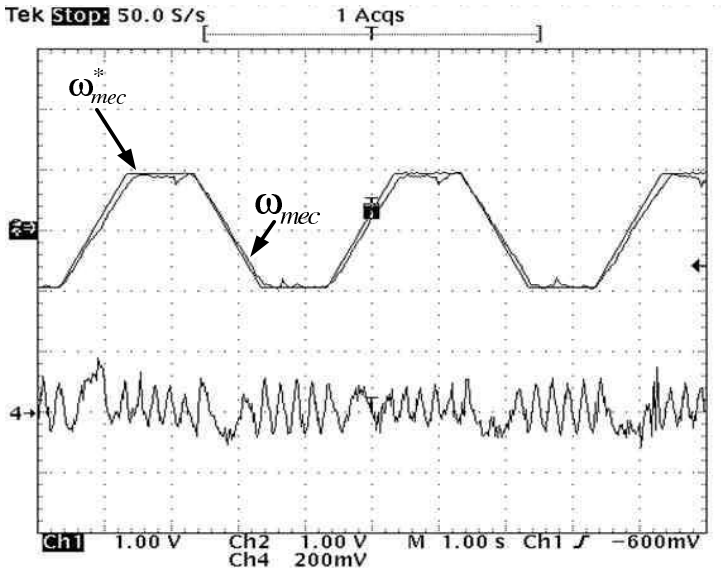

(a) DTC - speed with complex controller (13 rad/s.div).

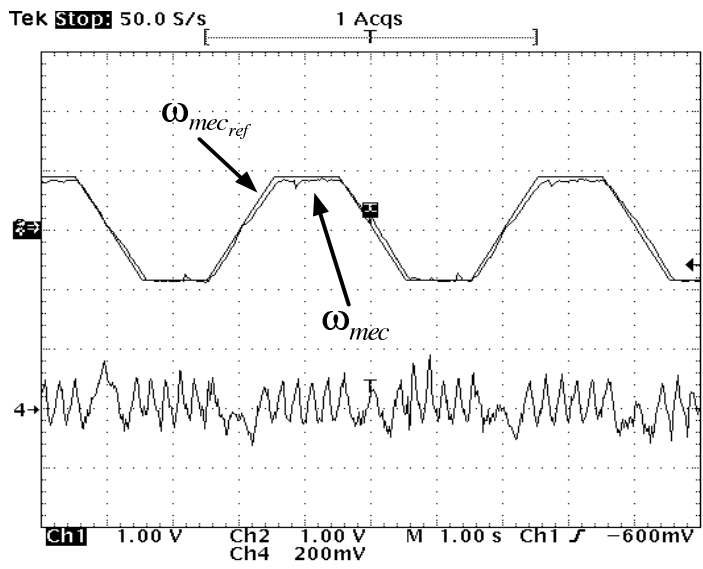

(b) DTC - speed with PI controller (13 rad/s.div).

Figure 8: Speed forwad and reversal operation and current of phase $a(10 \mathrm{~A} / \mathrm{div})$.

could be necessary to prepare a table with several complex gains designed for each speed desired or to specifically speed range. Thus, the complex vector notation and the complex controller can become an interesting tool for the implementation of three-phase induction motor direct control drives. Operation at low speed was explored but it requires a more complete study in the future.

\section{ACKNOWLEDGEMENT}

The authors would like to thank CAPES for the financial support of this research through a scholarship offered to one of the authors. 


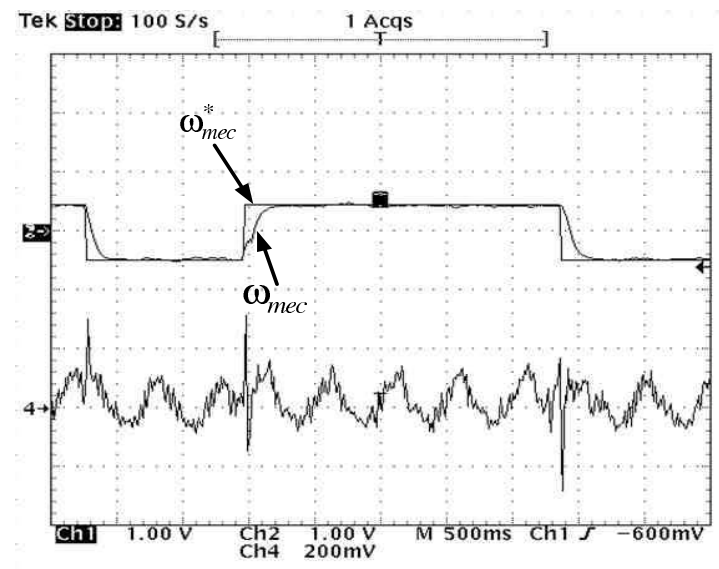

(a) DTC - speed with complex controller (12.57 rad/s.div)

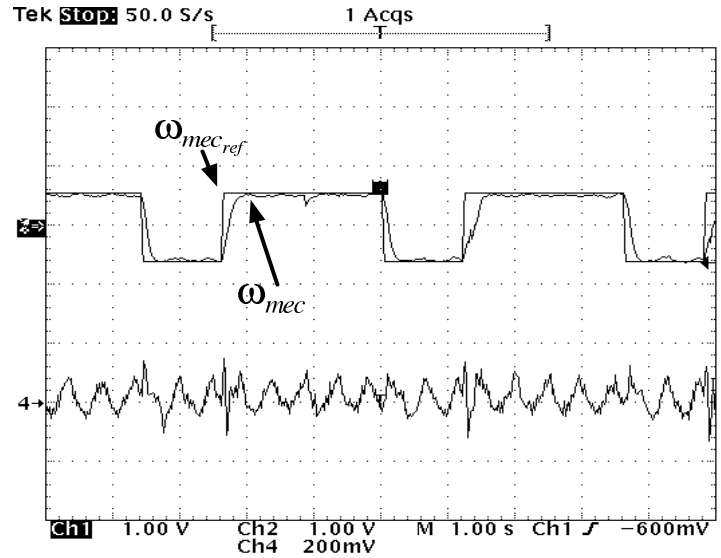

(b) DTC - speed with PI controller (12.57 rad/s.div)

Figure 9: Speed response to step operation and current of phase $a(6 \mathrm{~A} / \mathrm{div})$.

\section{APPENDIX}

Three-phase induction motor variables and parameters: $P N=2.3 \mathrm{~kW} ; V_{N}=220 \mathrm{~V} ;$ Poles $=4 R_{1}=2.229$ $\Omega ; R_{2}=1.522 \Omega ; L_{m}=0.238485 H ; L_{1}=0.2470 H$; $L_{2}=0.2497 \mathrm{H} ; J=0.0067 \mathrm{Kgm}^{2}$.

\section{REFERENCES}

Briz, F., degener, M. W. e Lorenz, R. D. (2000). Analysis and design of current regulators usin complex vectors, IEEE Trans. Ind. Applicat. 36: 817-825.

Buja, G. S. e Kazmierkowski, M. P. (2004). Direct torque control of pwm inverter-fed ac motors - a survey, IEEE Trans. Ind. Electronics 51(4): 744757.

Cad, M. M. (2000). Estratégias de modelagem dinâmica e simulação computacional do motor de indução trifásico, Dissertação de mestrado, Escola de Engenharia de São Carlos, USP - Universidade de São Paulo.

Depenbrock, M. (1988). Direct self-control(dsc) of inverter-fed induction machine, IEEE Trans. Power Electronics 3(4): 420-429.

Holtz, J. (1995). The representation of ac machine dynamics by complex signal flow graphs, IEEE Trans. Ind. Electron. 42: 263-271.

Holtz, J., Quan, J., Pontt, J., Rodríguez, J., newman, P. e Miranda, H. (2004). Design of fast and robust current regulators for high-power drives based on complex state variables, IEEE Trans. Ind. Applications 40: 1388-1397.

$\mathrm{Hu}, \mathrm{J}$. e Wu, B. (1998). New integration algorithms for estimating motor flux over wide speed range, IEEE Trans. on Power Electronics 13(5): 969-977.

Kovács, P. K. e Rácz, E. (1984). Transient Phenomena in Electrical Machines, Amsterdam, The Netherlands: Elsevier.

Lins, Z. D. (2001). Controle direto de torque para motores de indução - estudo e implementação, Tese doutorado, Faculdade de Engenharia Elétrica e Computação, Unicamp - Universidade Estadual de Campinas.

Stojic, D. M. e Vukosavic, S. N. (2005). A new induction motor drive based on the flux vector acceleration method, IEEE Trans. Ind. Applications 20(1): 173180.

Takahashi, I. e Noguchi, T. (1986). A new quickresponse and high-efficiency control strategy of an induction motor, IEEE Trans. Ind. Applications IA-22(5): 820-827.

Xu, X., Donker, R. D. e Novotny, D. W. (1988). A stator flux oriented induction machine drive, $P E S C^{\prime} 88$ Conference Record pp. 870-876.

Xue, Y., Xu, X., Halbetler, T. G. e Divan, D. M. (1990). A low cost stator flux oriented voltage source variable speed drive, Conference Record of the 1990 IEEE Industrial Aplications Society Annual Meetting 1: 410-415.

Yamamura, S. (1992). Spiral Vector Theory of AC Circuits and Machines, Clarendon Press OXFORD. 